\title{
A case study of a low-level jet during OPALE
}

\author{
H. Gallée, H. Barral, E. Vignon, and C. Genthon \\ CNRS/UJF - Grenoble 1, Laboratoire de Glaciologie et Géophysique de l'Environnement (LGGE), France \\ Correspondence to: H. Gallée (gallee@lgge.obs.ujf-grenoble.fr) and C. Genthon (genthon@lgge.obs.ujf-grenoble.fr)
}

Received: 13 October 2014 - Published in Atmos. Chem. Phys. Discuss.: 10 December 2014

Revised: 7 April 2015 - Accepted: 5 May 2015 - Published: 8 June 2015

\begin{abstract}
A case study of a low-level jet (LLJ) during the OPALE (Oxidant Production over Antarctic Land and its Export) summer campaign is presented. It has been observed at Dome C (East Antarctica) and is simulated accurately by the three-dimensional version of the Modèle Atmosphérique Régional (MAR). It is found that this low-level jet is not related to an episode of thermal wind, suggesting that Dome $\mathrm{C}$ may be a place where turbulence on flat terrain can be studied.
\end{abstract}

\section{Introduction}

Low-level jets (LLJs) have been observed and studied for a long time (see e.g. Davies, 2000; Cuxart and Jimenez, 2007; Banta et al., 2003). Their interest may be related to the need for a better understanding of the atmospheric boundary layer. On the one hand, they are suspected of generating additional turbulence. On the other hand, their behaviour may have an impact among others on the management of wind turbines, and bird migration (Van de Wiel et al., 2010). Following Blackadar (1957) and Van de Wiel et al. (2010), LLJs may be due to the onset of an inertial oscillation when the turbulence force suddenly decreases at the end of day-time. LLJs have been observed over the Weddel Sea (Antarctica) (Andreas et al., 2000).

A wind speed maximum near the surface has also been observed at the South Pole during ANTCI (Neff et al., 2008). In contrast to the LLJs observed at Dome C, it is associated with events of inversion winds. Indeed, the South Pole is situated on a slope, while Dome C is not. The LLJ at Dome C is related to the pressure gradient force (PGF) extending well above the boundary layer, while at the South Pole, the wind speed maximum is caused by the downslope PGF developing only in the bulk of the inversion wind layer. Another difference is that there is no diurnal cycle at the South Pole. Conse- quently, a LLJ could not develop there at the end of day-time, when turbulence shuts down. Possibly a LLJ could develop at the South Pole with a rapid stabilisation of the atmosphere associated with changes in synoptic-scale conditions. A consequence of the absence of a diurnal cycle is that turbulence in the stable boundary layer of the South Pole may reach an equilibrium, while this is not the case at Dome $\mathrm{C}$ during summer. Note that Neff et al. (2008) mention that the behaviour of nitrous oxide (NO) below the wind speed maximum they observe is not fully understood, since it could depend (but not always) on an accumulation process of NO over a thin drainage flow whose thickness increases gradually before it reaches the South Pole. In our case no drainage flow reaches Dome $\mathrm{C}$, so that the above-mentioned accumulation process does not exist.

A common point between LLJs associated with an inertial oscillation and the observations of Neff et al. (2008) is that the wind shear is zero at the jet maximum, so that turbulent transport could not exist through the jet core (the gradient Richardson number is "infinite" there). Note however that the LLJ at Dome $\mathrm{C}$ forms at a height where turbulence has already shut down, so that the LLJ is not strictly necessary for precluding vertical turbulent transport there. In contrast, the wind speed maximum at the South Pole is associated with the turbulent inversion winds, and could play a more important role in causing the shutdown of turbulence.

Finally, the shutdown of turbulence by a wind speed maximum remains an open question. Indeed, turbulence bursts have been simulated through a jet core in a LES (large eddy simulation) by Cuxart and Jiménez (2007), but only when the wind and air temperature near the surface are prescribed in their model.

In this note we consider a case study of a LLJ happening at Dome C during the night of 16-17 December 2011 (during the OPALE campaign) and accurately simulated by MAR. 


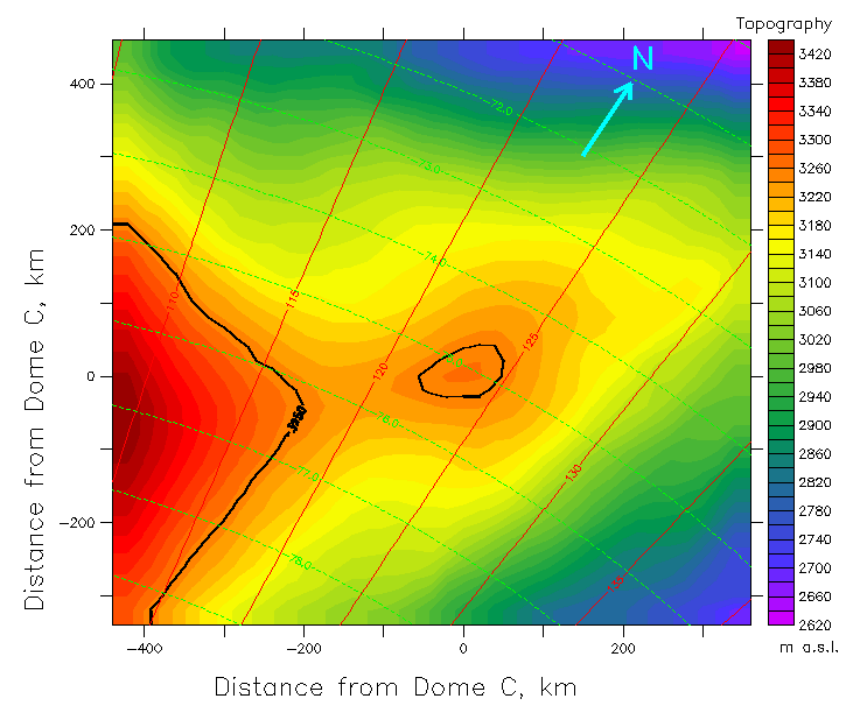

Figure 1. MAR integration domain and topography (colour). Solid line represents the $3250 \mathrm{~m}$ isocontour.

The model has been satisfactorily validated for the OPALE campaign in Gallée et al. (2015). The objective here is to focus on the driving forces of a LLJ at Dome C.

\section{The model}

The model used is MAR (Modèle Atmosphérique Régional). It is described and set up as in Gallée et al. (2015). A summary is given here.

MAR is a hydrostatic primitive equations model using finite difference schemes (Gallée and Schayes, 1994). The terrain following normalised pressure is used to take into account topography. Turbulence is parametrised by using two prognostic equations for turbulent kinetic energy and its dissipation (Duynkerke, 1988; Bintanja, 2000). The prognostic equation of dissipation allows one to relate the mixing length to local sources of turbulence and not only to the surface. Finally, the relationship between the turbulent diffusion coefficient for momentum and scalars (Prandtl number) is dependent on the Richardson number, according to Sukoriansky et al. (2005). An explicit cloud microphysical scheme describes exchanges between water vapour, cloud droplets, cloud ice crystals (concentration and number), snow particles and rain drops (Gallée, 1995).

The horizontal domain covers an area of about $800 \mathrm{~km} \times$ $800 \mathrm{~km}$ surrounding Dome C. The $x$ axis of the MAR domain is directed from the south-west to the north-east (see Fig. 1 see also Fig. 3 for a localisation of Dome C over the Antarctic ice sheet). Horizontal grid size is $20 \mathrm{~km}$. There are 60 levels, with a vertical discretisation in the lower troposphere of $2 \mathrm{~m}$. It decreases with altitude above $32 \mathrm{~m}$ a.g.l., reaching $50 \mathrm{~m}$ at $300 \mathrm{~m}$ a.g.l. and $400 \mathrm{~m}$ at $3000 \mathrm{~m}$ a.g.l.
The simulation is started on 1 November 2011 and the model is not reinitialised until the end of the experiment (end of January 2012). Thus the simulation is sufficiently long to allow the influence of lateral boundary conditions to reach the central part of the domain, in contrast to what happens in a simulation starting from prescribed initial conditions, and lasting a few hours or days only. As lateral boundary conditions are over-specified in a limited area model, they may distort its solution and cause some differences between the simulation and the observation. This point will be illustrated in the next section.

\section{The low-level jet}

\subsection{Overview}

It was possible to observe LLJs occurring only at a height below the top of the tower. As LLJs occur where turbulence shuts down, this means that in these cases stabilisation of the vertical column of air is strong, i.e. when the wind shear is not too large and a strong radiational cooling of the surface occurs.

Observed and simulated LLJs during the OPALE period (12 December 2011-14 January 2012) are listed in Table 1. They are obtained by searching from below the lowest wind speed maximum below the highest level of the tower. Note that the vertical resolution of the model $(2 \mathrm{~m})$ is higher than that of the observations (six levels, respectively at 3.5, 10.8, 18.2, 25.6, 32.9 and $42.1 \mathrm{~m}$ ). Consequently, the estimation of the height of the LLJ in the observations may be very crude. No LLJ is simulated or observed in January 2012, but no observations at the tower were made between 1 and 9 January, and generally we did not get clear sky conditions in the first half of January 2012 (see e.g. Fig. 2a of the companion paper - Gallée et al., 2015). MAR simulated a LLJ on 15 December below the top of the tower, while it was very weak in the observation. No LLJ was simulated below the top of the tower on 26, 27 and 28 December, when MAR underestimated cloud cover and consequently overestimated day-time solar warming the day before. This caused an overestimation of turbulence and precluded the formation of a shallow inversion layer during night-time. In short, the good simulation of a LLJ by MAR or not in December 2011 was mainly the result of the good behaviour of turbulence or not in the model, which itself results mainly from the good behaviour or not of the simulated cloud cover. LLJs are more sensitive to turbulence than the winds simulated near the surface. Consequently, the evaluation of their behaviour may help us in evaluating vertical mixing of chemical species. Of course, a longer time series must be analysed in order to confirm this result. Note that statistics of observed LLJs at Dome C have already been given in Barral et al. (2014). 
Table 1. Observed and simulated LLJs at Dome C during OPALE. $h$ is the height of the LLJ.

\begin{tabular}{|c|c|c|c|c|c|c|c|}
\hline \multicolumn{4}{|c|}{ Observation } & \multicolumn{4}{|c|}{ Simulation } \\
\hline \multicolumn{2}{|c|}{ Date } & \multirow{2}{*}{$\begin{array}{r}\mathrm{h} \\
(\mathrm{m}) \\
18.2\end{array}$} & \multirow{2}{*}{$\begin{array}{r}\begin{array}{r}\text { LLJ } \\
\left(\mathrm{m} \mathrm{s}^{-1}\right)\end{array} \\
4.33\end{array}$} & \multicolumn{2}{|c|}{ Date } & \multirow{2}{*}{$\begin{array}{r}\mathrm{h} \\
(\mathrm{m}) \\
08.0\end{array}$} & \multirow{2}{*}{$\begin{array}{r}\begin{array}{r}\text { LLJ } \\
\left(\mathrm{m} \mathrm{s}^{-1}\right)\end{array} \\
4.34\end{array}$} \\
\hline $12 \mathrm{Dec}$ & $21: 00$ & & & $13 \mathrm{Dec}$ & 00:00 & & \\
\hline $14 \mathrm{Dec}$ & $03: 30$ & 18.2 & 3.26 & $14 \mathrm{Dec}$ & $04: 30$ & 10.0 & 3.80 \\
\hline $15 \mathrm{Dec}$ & 00:00 & 25.6 & 5.40 & $15 \mathrm{Dec}$ & 01:00 & 10.0 & 5.44 \\
\hline $16 \mathrm{Dec}$ & 01:00 & 18.2 & 5.59 & $16 \mathrm{Dec}$ & 01:00 & 08.0 & 4.83 \\
\hline $17 \mathrm{Dec}$ & 01:00 & 18.2 & 7.56 & $17 \mathrm{Dec}$ & 02:00 & 14.0 & 6.52 \\
\hline $17 \mathrm{Dec}$ & $23: 30$ & 32.9 & 8.53 & $18 \mathrm{Dec}$ & $00: 30$ & 22.0 & 8.26 \\
\hline $22 \mathrm{Dec}$ & $05: 30$ & 25.6 & 6.40 & $22 \mathrm{Dec}$ & $05: 30$ & 14.0 & 4.22 \\
\hline $22 \mathrm{Dec}$ & $00: 30$ & 18.2 & 1.02 & $22 \mathrm{Dec}$ & $23: 30$ & 10.0 & 3.68 \\
\hline $25 \mathrm{Dec}$ & 00:00 & 18.2 & 6.47 & $25 \mathrm{Dec}$ & 00:00 & 16.0 & 6.85 \\
\hline $26 \mathrm{Dec}$ & $04: 30$ & 25.6 & 7.70 & $26 \mathrm{Dec}$ & $04: 30$ & 16.0 & 5.72 \\
\hline $26 \mathrm{Dec}$ & 06:00 & 25.6 & 6.14 & & & & \\
\hline $27 \mathrm{Dec}$ & $00: 30$ & 18.2 & 6.59 & & & & \\
\hline $28 \mathrm{Dec}$ & $02: 30$ & 32.9 & 7.12 & & & & \\
\hline $28 \mathrm{Dec}$ & 04:00 & 18.2 & 6.72 & & & & \\
\hline $29 \mathrm{Dec}$ & $04: 30$ & 25.6 & 10.6 & & & & \\
\hline
\end{tabular}

Hereafter we focus on a well-marked case study which is accurately simulated, in order to infer in a deeper way how to evaluate the simulation of a LLJ by a 3-D model.

\subsection{The case study}

We consider the same experiment as in Gallée et al. (2015) and the observations which have been performed on a $45 \mathrm{~m}$ tower with six levels of measurement (Genthon et al., 2010, 2013). The situation of 16-17 December 2011 has been chosen because the model simulates a LLJ at a height where it has been observed. Another case study occurring on 26 December 2011 in the evening is presented in Gallée et al. (2015). In that case the model overestimates significantly the height at which the LLJ is observed, mainly because it fails in simulating the surface energy balance during day-time, in conjunction with an underestimation of the cloud cover by the model. In contrast, the simulated surface energy balance is much better simulated by MAR on 16 December, when the downward longwave radiation flux (DLW) is only slightly underestimated.

The MAR simulation for 16-17 December 2011 is compared with observation in Fig. 2. The LLJ is simulated at 01:00 LT on 17 December at 14 ma.g.l. This height is comparable to that found in the observations $(18 \pm 4 \mathrm{~m})$ as we have observations at $10.8,18.2$ and 25.6 ma.g.1. Both simulation and observation show a strong wind shear beneath the jet and almost no wind shear above. The temperature profiles are similar, with the same evolution of the intensity and depth of the inversion, although the depth is slightly underestimated.

Vertical profiles of simulated temperatures, wind speeds and wind directions are compared in Fig. 3 to the observa-
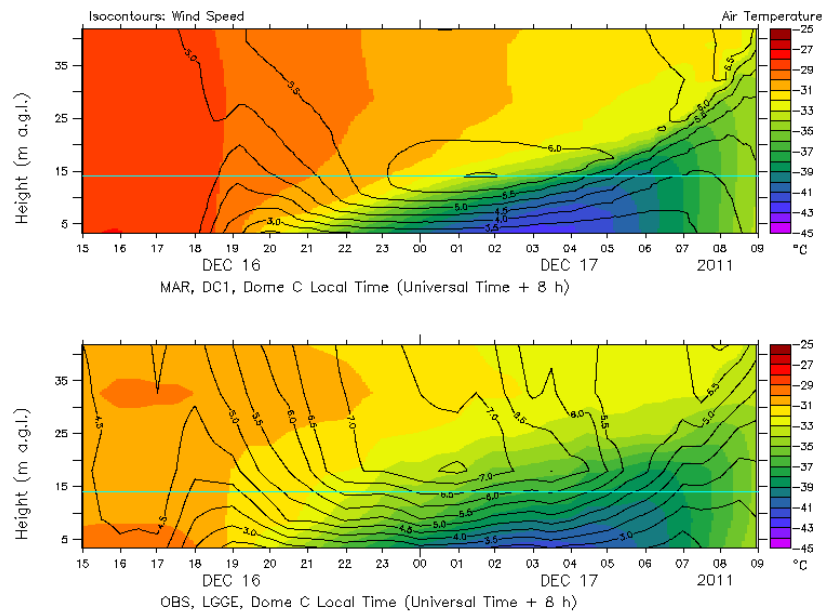

Figure 2. Temperature (colour) and wind speed (isocontours) at the Dome C tower, simulated by MAR on 16-17 December 2011 (upper panel) and observed (lower panel). Local Time LT (Universal Time UT $+8 \mathrm{~h}$ ) is used. The simulated jet level is at $z=14 \mathrm{ma.g.l}$. (shown by a cyan line in both panels).

tions made at the tower for 16:00 and 24:00 LT. Temperatures are overestimated during day-time and overestimated above the LLJ during night-time. The overestimation above the LLJ during night-time may be due to an underestimation of turbulence by the E-e model. Similarly, momentum mixing seems to be well simulated during day-time, but the wind speed is underestimated at midnight above the LLJ, as the temperature. Possibly this is linked to the representation of large-scale winds in the model (see Fig. 5). Wind direction seems to be well simulated. 

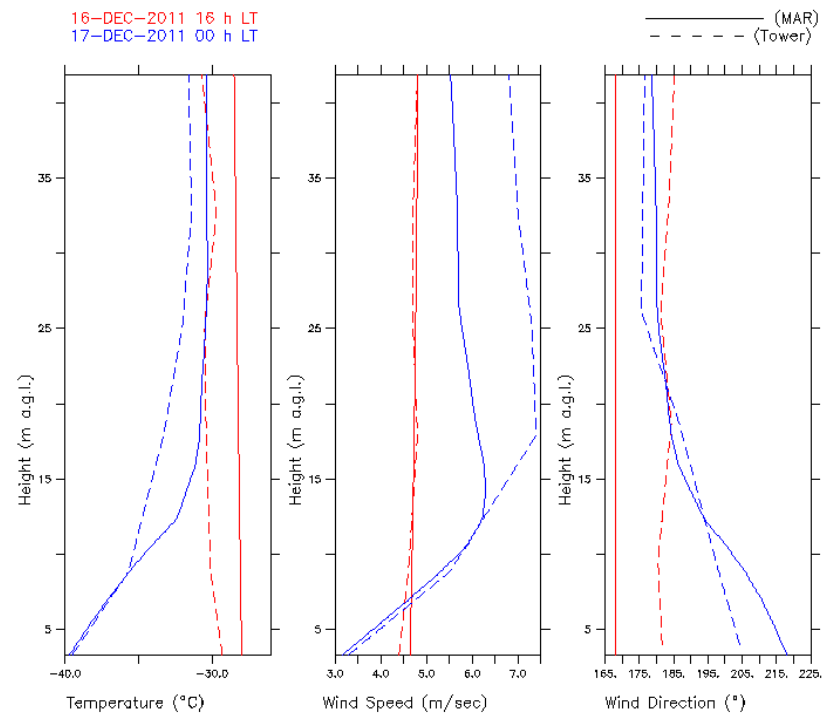

Figure 3. Vertical profiles of simulated temperatures, wind speeds and wind directions on 16 December 2011 at 16:00 LT and midnight.

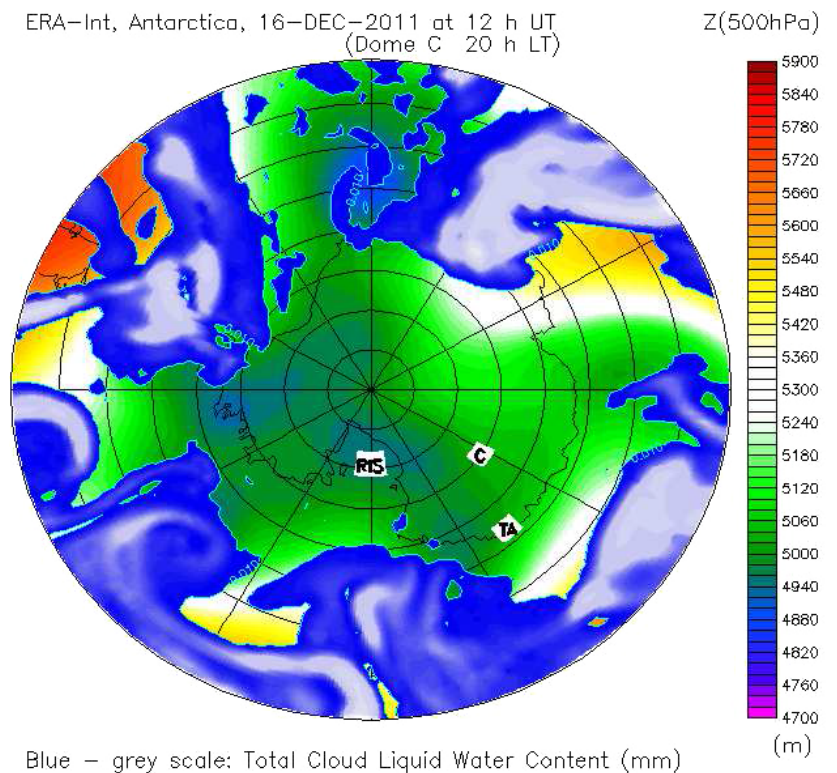

Figure 4. $500 \mathrm{hPa}$ geopotential (m) over Antarctica on 16 December 2011 at 12:00 UT (colour key to the right). Total cloud liquid water content (TCLW), from 0.01 (dark blue) to $1.2 \mathrm{~mm}$ (grey), is also shown. The TCLW $0.01 \mathrm{~mm}$ isocontour is also represented by a cyan line. Dome C is indicated by the letter "C". Terre Adélie and the Ross Ice Shelf are indicated respectively by "TA" and "RIS".

The behaviour of the MAR turbulent scheme is also discussed in Gallee et al. (2015), with the conclusion that the underestimation of turbulence may be partly due to the underestimation of DLW, which is responsible for an overesti-
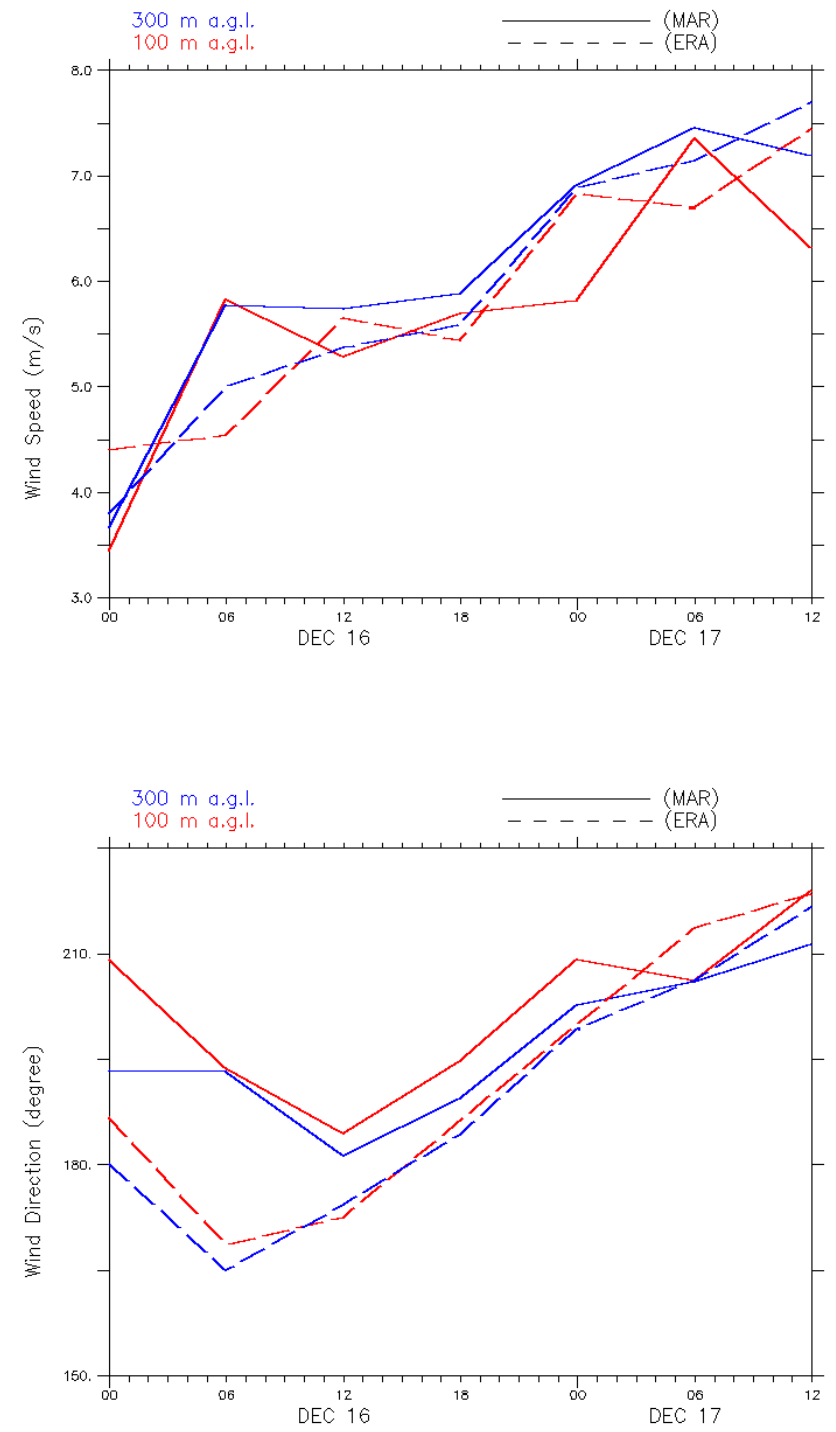

Figure 5. Comparison between the analysed wind speed (top) and direction (bottom) and the simulation, at $100 \mathrm{~m}$ a.g.l. and $300 \mathrm{~m}$ a.g.l. Note that Universal Time is used.

mation of the vertical stability near the surface during nighttime.

We now have a look at the general conditions prevailing during this LLJ.

The synoptic-scale situation prevailing on 16-17 December in the vicinity of Dome C and illustrated by the $500 \mathrm{hPa}$ geopotential map consists of a low-pressure centre situated on the Ross Ice Shelf, with a secondary minimum on Adélie Land (see Fig. 4 for the situation at 12:00 UT on 16 December). The intensity of both diminishes with time while they remain stationary. Consequently, the synoptic-scale pressure gradient force is directed from the south-west to the northeast at Dome C, while synoptic-scale (geostrophic) winds 
blow from the Antarctic plateau towards Dome $\mathrm{C}$ during this period.

It appears that the model captures reasonably well the wind vector above the tower, as can be seen from a comparison with the forcing (ERA-Interim) at 100 and $300 \mathrm{~m}$ a.g.1. The error in the wind speed and direction may amount respectively to $1.5 \mathrm{~m} \mathrm{~s}^{-1}$ and $30^{\circ}$ (see Fig. 5). Note that universal time is used in the figure and that the crude time discretisation of ERA forcing (data provided every $6 \mathrm{~h}$ only) influences strongly the time evolution of the simulated wind speed and direction. Indeed, MAR data are provided with a time resolution of $10 \mathrm{~min}$, but exhibit significant changes only every $6 \mathrm{~h}$.

Let us now look at the simulation along the slope ( $x$ axis) and consider the pressure gradient force (PGF). Rather than represent the norm of the PGF horizontal vector $\left(\mathrm{PGF}_{u}, \mathrm{PGF}_{v}\right)$, we represent the contribution of the PGF to the wind speed intensity $(V)$. This allows us to get more insight into the role of the different forces in accelerating the wind speed at the end of day-time. This contribution may be obtained by multiplying the equations for $u$ and $v$ by $u$ and $v$ respectively and summing them in order to obtain an equation for the local variation of the kinetic energy with time.

We get (see Appendix for more details)

$$
\begin{aligned}
\frac{\partial V}{\partial t} & =\underbrace{\frac{u}{V} \mathrm{ADV}_{u}+\frac{v}{V} \mathrm{ADV}_{v}}_{\text {Advection Contribution }}+\underbrace{\frac{u}{V} \mathrm{PGF}_{u}+\frac{v}{V} \mathrm{PGF}_{v}}_{\text {PGF Contribution }} \\
& +\underbrace{\frac{u}{V} F_{u}+\frac{v}{V} F_{v}}_{\text {Turbulence Contribution }},
\end{aligned}
$$

where $\mathrm{ADV}_{u}$ and $\mathrm{ADV}_{v}$ are the contributions from advection to $u$ and $v$ respectively. Similarly, $F_{u}$ and $F_{v}$ are the contributions from turbulence. Of course, the contribution of the Coriolis force to the kinetic energy is zero, and so it is the same for the wind speed. Note also that a zero PGF contribution to the wind speed evolution should be related to the fact that the PGF vector is orthogonal to the wind vector.

Vertical profiles of advection, PGF, the contribution of turbulence and horizontal diffusion, and their sum at 16:00 and 24:00 LT are shown in Fig. 6. The last is interpreted as the tendency of the wind speed. These profiles are roughly homogeneous along the vertical during day-time (16:00 LT), with PGF counterbalancing roughly the turbulent contribution. A similar equilibrium between PGF and the turbulent contribution exists at midnight below the LLJ, but their absolute values are reinforced. The contribution of turbulence is zero at the level of the LLJ and just above, where turbulence production by the wind shear is almost zero. Horizontal diffusion contributes negatively (positively) below (above) the height of the jet core. The negative contribution in the bulk of the boundary layer could be related to the weakening of the wind speed on the slope directed towards negative $x$ values during night-time. The maximum in the wind speed tendency

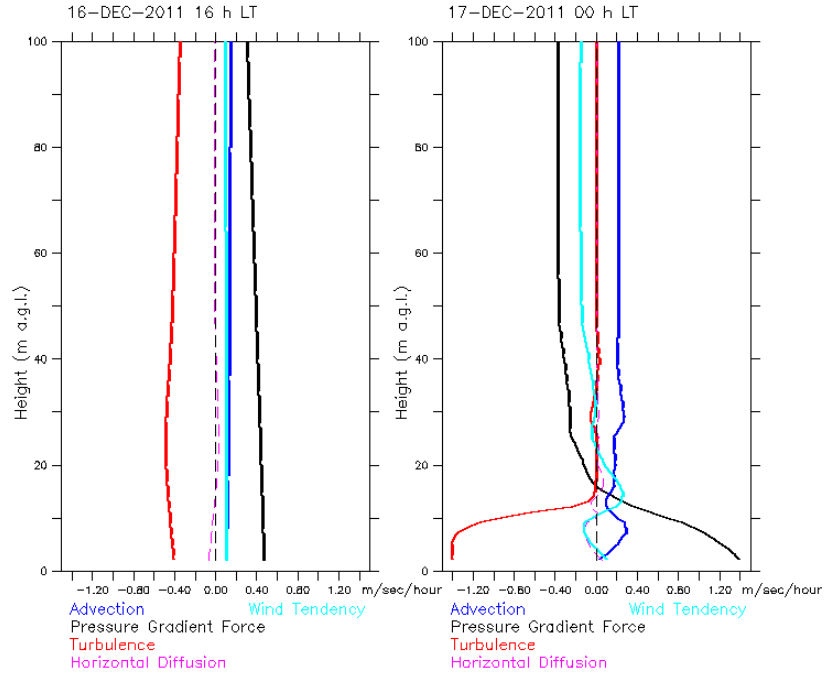

Figure 6. Vertical profiles of the contributions to the wind speed of PGF, advection, turbulence and horizontal diffusion.

results from the dominant contribution of the PGF just above the boundary layer, i.e. where the contribution of turbulence cancels.

The wind speed $V$, the wind direction, the contribution of the pressure gradient force (PGF) to the wind speed and the direction of the $\mathrm{PGF}$ vector $\left(\mathrm{PGF}_{u}, \mathrm{PGF}_{v}\right)$ simulated by the model are shown in Fig. 7a (day-time) and b (night-time). The (PGF contribution to the) wind speed and the direction of the wind speed (direction of the PGF vector) are shown respectively by contour lines and by colours.

A positive PGF contribution to the wind speed, as defined in Eq. (1), means that the PGF is responsible for an acceleration of the wind speed. The wind is roughly from the southsouth-east during day-time (Fig. 7a, 16:00 LT). It comes from a slightly more southerly direction only above the jet level (14 m a.g.l.) during night-time (Fig. 7b, 24:00 LT) and blows from the south-west below. The changes in the wind direction between 16:00 and 24:00 LT result from a change in the direction of the synoptic-scale PGF vector $\left(\mathrm{PGF}_{u \text {, syn }}\right.$, $\mathrm{PGF}_{v \text {,syn }}$ ) from south-westerly to westerly. The wind direction well above the jet level $14 \mathrm{ma.g} .1$. was influenced by turbulence at 16:00 LT, with a direction between the direction of the geostrophic wind (south-easterly) and that of the PGF vector (south-westerly). At 24:00 LT, it is no longer influenced above the jet level by turbulence and comes in the geostrophic wind direction (southerly at that time), while below the jet level it is still influenced by turbulence and comes between the geostrophic wind direction and the PGF vector direction (westerly).

The reason why the PGF contributes to an acceleration of the wind speed up to $14 \mathrm{ma.g} .1$. at Dome C (isocontours of Fig. 7b, lower panel, at 24:00 LT and $x=0 \mathrm{~km}$ ) comes from the fact that the wind direction is not geostrophic, because it is influenced by turbulence generated by surface friction 

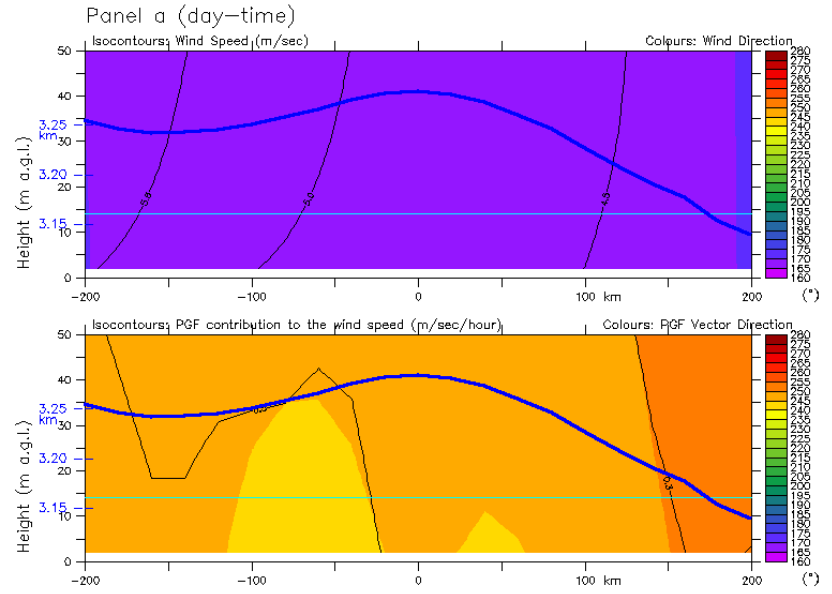

MAR, DC1, Dome C, 16-DEC-2011, 16 LT (8 UT)
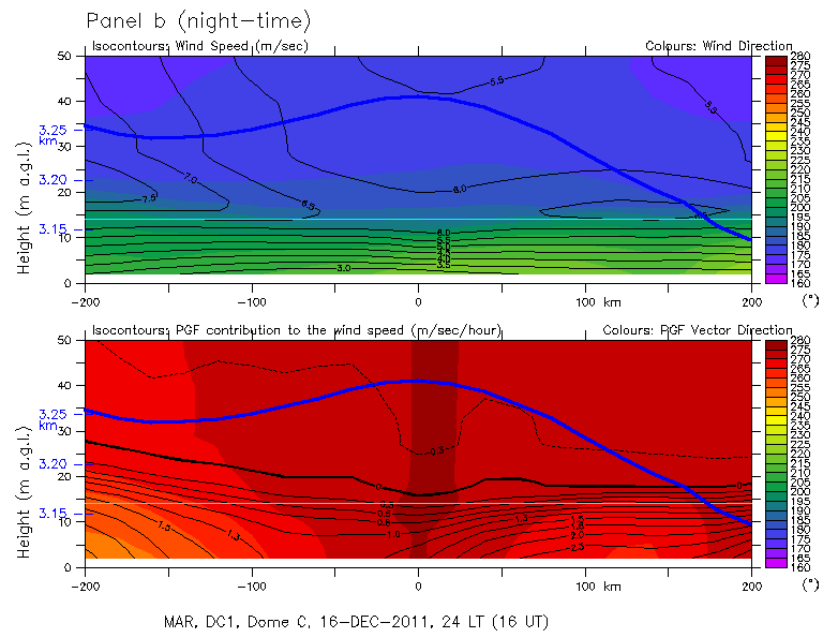

Figure 7. (a) Wind (top) and PGF (bottom) at the end of day-time (16:00 LT), along the $x$ axis. The PGF contribution to the wind speed is defined in Eq. (1). PGF vector refers to $\left(\mathrm{PGF}_{u}, \mathrm{PGF}_{v}\right)$. Domain topography is shown by the thick blue line. The distance from Dome C is in $\mathrm{km}$. The simulated jet level is at $z=14 \mathrm{ma}$ a.g.l. (cyan line). (b) Same as in (a) but at midnight.

up to this height. In fact, turbulence deflects the wind vector, forcing it to blow from a direction in which it may be accelerated by the PGF. The acceleration occurs when turbulence shuts down at the end of the day. Then the increasing wind speed is responsible for an increase in the Coriolis force and the wind starts to turn to the left (anti-clockwise rotation). This is not the case at this time above $14 \mathrm{~m}$, where the wind direction is close to being geostrophic, i.e. the wind vector is roughly perpendicular to the PGF vector.

Note in Fig. $7 \mathrm{~b}$ the weakening of the wind speed below the jet level (14 ma.g.l.) from day to night, which is linked to a strong weakening of turbulence well above the surface led by a strong increase in the vertical stability of the atmosphere. In contrast, the onset of a LLJ is responsible for

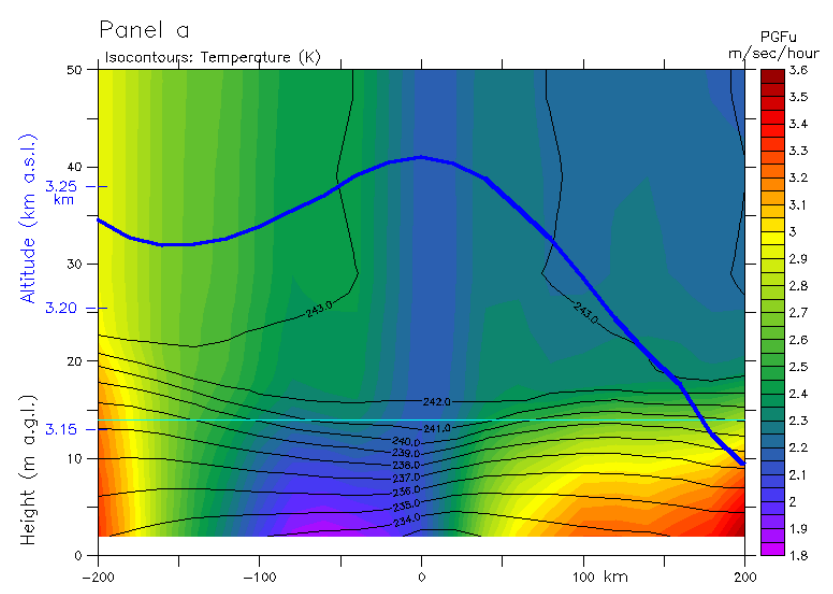

MAR, DC1, Dome C, 17-DEC-2011 0 hLT (16-DEC-2011 16 hTU)

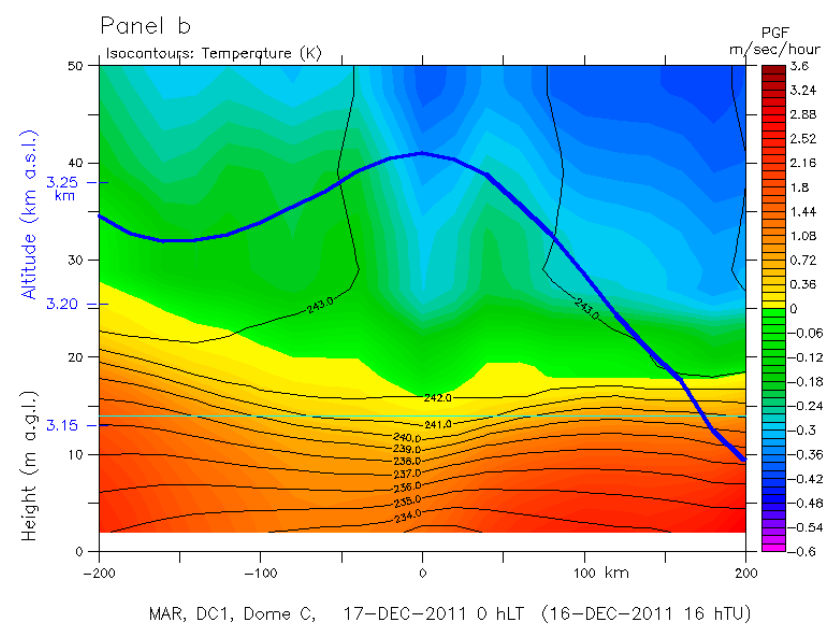

Figure 8. (a) Temperature and $\mathrm{PGF}_{u}$ at midnight, along the $x$ axis. Distance is from Dome C. (b) Temperature and PGF, at midnight, along the $x$ axis. Distance is from Dome C.

an increase in the vertical wind shear between the ground and $14 \mathrm{ma}$ a.g.l., so that the weakening of turbulence from day to night may be slightly limited. In fact, a possible contribution of the LLJ to turbulence in our case seems insignificant. Rather, turbulence during night-time on 16-17 December 2014 is essentially generated by the surface friction. Also, the strong stability of the atmosphere at Dome C during night-time explains why the LLJ is situated very close to the surface and may be observed over a relatively short tower.

Note also the occurrence of the wind speed maxima with downslope wind direction just above 14 ma.g.l. at 24:00 LT (see e.g. Fig. 7b, top panel, $x=-200 \mathrm{~km}$ and $x=130 \mathrm{~km}$ ). These maxima may correspond to an acceleration of the wind when turbulence in the boundary layer weakens, so that the downslope flow behaves like an advective-gravity flow (see Mahrt, 1982). 


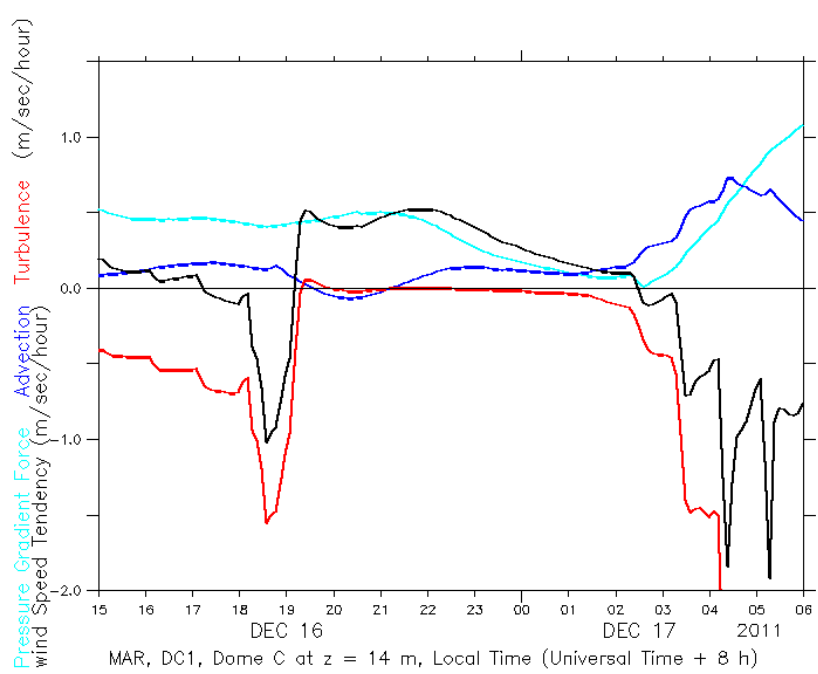

Figure 9. Simulated contribution of the forces to the wind speed, 14 ma.g.1. at Dome C on 16-17 December 2011. Local Time LT (Universal Time UT $+8 \mathrm{~h}$ ) is used. The shutdown of turbulence occurs at 19:00 LT.

The component of the PGF along the $x$ axis $\left(\mathrm{PGF}_{u}\right)$ on 16 December at 24:00 LT is compared to the temperature in Fig. 8a. It is found that $\mathrm{PGF}_{u}$ intensifies below 14 ma.g.l., except between -150 and $0 \mathrm{~km}$, where the local slope is in the opposite direction of its general direction. The variations of $\mathrm{PGF}_{u}$ along the $x$ axis below $14 \mathrm{ma}$ a.g.l. occur in conjunction with a strong inversion, suggesting that they are associated with a downslope pressure gradient force. The variations of $\mathrm{PGF}_{u}$ also influence the variations of the contribution of the PGF to the wind speed (Fig. 7b, bottom). Nevertheless, neither the wind speed nor the wind direction is strongly affected by these variations (Fig. 7b, top). Inversion winds are generated by the downslope pressure gradient force. The thickness of the layer over which such a circulation occurs is generally no larger than a few tens of metres. Here the pressure gradient force is homogeneous along the vertical up to $2500 \mathrm{~m}$ a.g.l., suggesting that the synoptic-scale pressure gradient force is responsible for the general direction and intensity of the wind during that time. In other words, the inversion winds are not responsible for the wind field at Dome C during the LLJ case of 16-17 December 2014.

Note that the height of the strong inversion layer is the smallest and the inversion the strongest over the dome (Fig. 8), probably because of a progressive weakening of the flow which is counteracted upstream by the downslope contribution of the PGF along the $x$ axis, leading to a minimum in the wind speed and subsequently in the turbulent kinetic energy there. Probably the mass divergence caused by inversion winds all around Dome $\mathrm{C}$ during night-time also played a role.

The contribution of the PGF to the wind speed is also compared with the air temperature in Fig. 8b. From the discussion
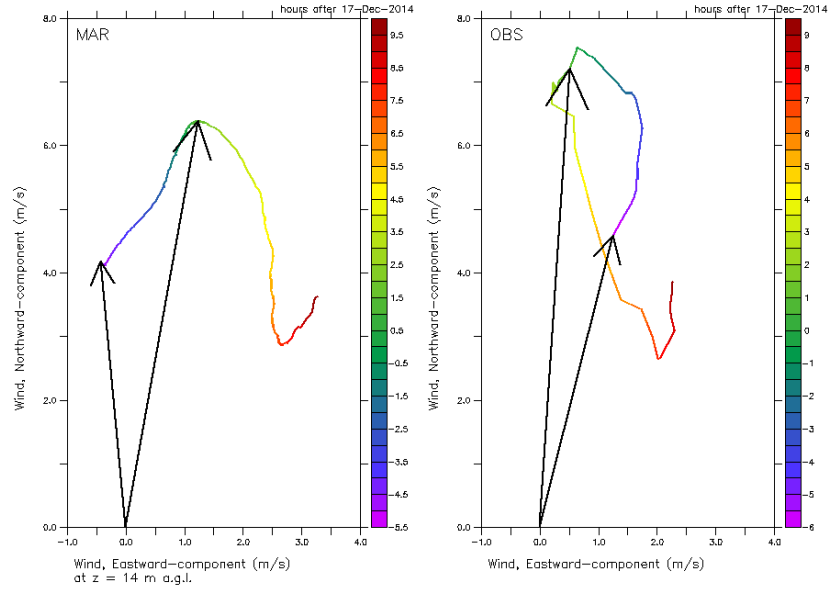

Figure 10. Wind hodograph at Dome C between 16 December 2011 19:00 LT and 17 December 2011 10:00 LT. Colours represent time in hours before/after 17 December midnight (negative/positive values). Arrows are plotted for 16 December 2011 19:00 LT and 17 December 2011 01:30 LT. Panel labeled "MAR": simulation at $z=14$ ma.g.l. Panel labeled "OBS": observations at level 3 of the tower $(z=17.9$ ma.g.1.).

above it appears that the change of sign of this contribution at Dome $\mathrm{C}$ (i.e. a change in the PGF contribution from an acceleration of the wind speed below $14 \mathrm{ma}$ a.g.l. to a slight deceleration above - pay attention to the colour scale) is not fortuitous. The 14 ma.g.l. level at Dome C is situated just below the sign reversal, i.e. where PGF still contributes to an acceleration of the wind speed. As the turbulence has already shut down there (see Fig. 6), we get good conditions for the formation of a LLJ.

In fact, the coincidence between the height of the change of sign of the PGF contribution to the wind speed and the top of the inversion layer during night-time may be due to a wind vector no longer orthogonal to the PGF in the inversion layer, but partly directed in the same direction as the wind vector. This is because turbulence there is generated by surface friction (Ekman wind) at that time. As a remnant of the wind direction change due to turbulence still exists in the upper part of the inversion layer, while turbulence contribution has already shut down, the PGF is in a position to accelerate the wind speed there.

Figure 9 illustrates the sudden shutdown of turbulence 14 ma.g.l. at Dome C after 19:00 LT, while the PGF is sustained. Such a situation has already been described by Blackadar (1957) as a source of an inertial oscillation. Indeed, it is found that the wind vector at $14 \mathrm{ma}$ a.g.l. initiates an anticlockwise rotation typical of an inertial oscillation until midnight (Fig. 10). This inertial oscillation is initiated by the sudden acceleration of the wind speed arising in conjunction with the sudden shutdown of turbulence. Contrary to the observations, the inertial oscillation vanishes around 01:30 LT in the model. A possible cause is that turbulence is again ac- 
tive at that time (Fig. 9). Another possible explanation is that the horizontal diffusion of the model damps the inertial oscillation as it does above 14 ma.g.l. Finally the overestimation of the westerly component of the wind vector after 01:30 LT could be due to an overestimation of the direction of the large scale wind in MAR (see Fig. 5).

Advection weakens between 18 and 21:00 LT and recovers after that time. The weakening of advection occurs mainly below $20 \mathrm{~m}$ a.g.l. and decreases progressively upwards. It is found that turbulence is higher to the south of (upstream) Dome $\mathrm{C}$ than at Dome $\mathrm{C}$ at $14 \mathrm{~m}$ a.g.l. (height of the jet core) and at 19:00 LT, while this is not the case at 22:00 LT. Also, at 19:00 LT the wind speed is higher upstream from Dome C than at Dome C. But at 17:00 LT the contribution of turbulence is smaller everywhere at $14 \mathrm{~m}$ a.g.l., while the wind speed is already higher upstream from Dome C. A possible mechanism upstream from Dome $\mathrm{C}$ could be a slight reinforcement of the wind speed during day-time by an upslope PGF, leading to a larger wind shear and turbulence there at the end of the day. While the inertial oscillation starts at Dome $\mathrm{C}$ due to the shutdown of turbulence, this is not yet the case upstream. Turbulence shuts down there only a few hours later. Consequently, the advection of momentum at Dome C could be weaker during a few hours at the end at the day. In short, if surface temperature is overestimated by the model, the reinforcement of the wind speed and turbulence upstream from Dome $\mathrm{C}$ during day-time could be overestimated by the model, and could lead to an overestimation of turbulence during a few hours at the end of day-time, a subsequent underestimation of advection at Dome C at the height of the LLJ, and an underestimation of its strength.

\section{Conclusions}

MAR simulates a low-level jet (LLJ) at Dome C on 1617 December 2011, as in the observations. It is the first time that a 3-D simulation of such a low-level jet over an ice sheet has been performed. The good behaviour of the model allows us to perform an analysis of the dynamical contributions (PGF, turbulence, advection) to the simulated wind speed.
It appears that the LLJ is generated when turbulence shuts down at the end of day-time, just above the turbulent layer, where the flow is still deflected from the geostrophic wind direction, blowing from higher to lower pressures. The LLJ seems not to be due to inversion winds over Dome C, but a reinforced LLJ is simulated by the model over the slopes near Dome C, where and when the downslope PGF reinforces the synoptic-scale PGF. In contrast, the model is not able to simulate the inertial oscillation after 01:30 LT. The cause is not yet firmly identified and this would be the subject of future work.

Finally, the height of the LLJ at Dome C is strongly dependent on the height of the turbulent layer, and thus its simulation is an indicator of the success or not of a model in simulating the intensity of turbulence under stable conditions. Cuxart et al. (2006) and Barral et al. (2014) show that a model overestimating turbulence overestimates the height of the wind speed maximum. Here a slight underestimation of turbulence by MAR possibly due to a slight underestimation of the downward longwave radiation flux during nighttime is responsible for a possible slight underestimation of the LLJ height. Vertical stratification of the atmosphere is strongly stable at Dome C during night-time, even in summer. During day-time the sensible heat fluxes are much larger than the latent heat fluxes, because of the low temperature and the subsequent very low capacity of the atmosphere to contain water (see e.g. King et al., 2006). Consequently, the conditions for developing a well-mixed layer during daytime are optimal. This means that the simulation of summer case studies at Dome C could help a lot in validating the turbulence scheme of an atmospheric model. Due to its particular location and available set of observations, Dome C was recently selected as the test site for the next Gewex Atmospheric Boundary Layer Studies (GABLS4) model intercomparison (see http://www.cnrm.meteo.fr/aladin/meshtml/ GABLS4/GABLS4.html). 
Appendix A: Contributions to the wind speed

Equations of horizontal motion in MAR read (Gallée and Schayes, 1994)

$$
\begin{aligned}
& \frac{\partial u}{\partial t}=-u \frac{\partial u}{\partial x}-v \frac{\partial u}{\partial y}-\dot{\sigma} \frac{\partial u}{\partial \sigma}+f v-\left.\frac{\partial \phi}{\partial x}\right|_{p}+F_{u} \\
& \frac{\partial v}{\partial t}=-u \frac{\partial v}{\partial x}-v \frac{\partial v}{\partial y}-\dot{\sigma} \frac{\partial v}{\partial \sigma}-f u-\left.\frac{\partial \phi}{\partial y}\right|_{p}+F_{v}
\end{aligned}
$$

where $f$ is the Coriolis parameter, $\phi=g z$ is the geopotential, and $F_{u}$ and $F_{v}$ are the contributions of turbulence to the wind components $u$ and $v$ respectively. Writing

$$
\begin{aligned}
& \operatorname{ADV}_{u}=-u \frac{\partial u}{\partial x}-v \frac{\partial u}{\partial y}-\dot{\sigma} \frac{\partial u}{\partial \sigma} \\
& \operatorname{ADV}_{v}=-u \frac{\partial v}{\partial x}-v \frac{\partial v}{\partial y}-\dot{\sigma} \frac{\partial v}{\partial \sigma} \\
& \mathrm{PGF}_{u}=-\left.\frac{\partial \phi}{\partial x}\right|_{p} \\
& \mathrm{PGF}_{v}=-\left.\frac{\partial \phi}{\partial y}\right|_{p}
\end{aligned}
$$

and multiplying the first equation by $u$ and the second by $v$, one gets the equation for the horizontal kinetic energy

$$
\begin{aligned}
u \frac{\partial u}{\partial t} & +v \frac{\partial v}{\partial t}=u \mathrm{ADV}_{u}+v \mathrm{ADV}_{v}+u \mathrm{PGF}_{u}+v \mathrm{PGF}_{v} \\
& +u F_{u}+v F_{v}
\end{aligned}
$$

where

$u \frac{\partial u}{\partial t}+v \frac{\partial v}{\partial t}=V \frac{\partial V}{\partial t}$.

Dividing both members of the equation for the horizontal kinetic energy by $V$, one gets

$$
\begin{aligned}
\frac{\partial V}{\partial t} & =\underbrace{\frac{u}{V} \mathrm{ADV}_{u}+\frac{v}{V} \mathrm{ADV}_{v}}_{\text {Advection Contribution }}+\underbrace{\frac{u}{V} \mathrm{PGF}_{u}+\frac{v}{V} \mathrm{PGF}_{v}}_{\text {PGF Contribution }} \\
& +\underbrace{\frac{u}{V} F_{u}+\frac{v}{V} F_{v}}_{\text {Turbulence Contribution }} .
\end{aligned}
$$


Acknowledgements. The OPALE project was funded by ANR (Agence National de Recherche) contract ANR-09-BLAN-0226.

Most of the computations presented in this paper were performed using the Froggy platform of the CIMENT infrastructure (https://ciment.ujf-grenoble.fr), which is supported by the RhôneAlpes region (grant CPER07_13 CIRA), the OSUG@2020 labex (reference ANR10 LABX56) and the Equip@Meso project (reference ANR-10-EQPX-29-01) of the Investissements d'Avenir programme supervised by the Agence Nationale pour la Recherche.

This work was also granted access to the HPC resources of IDRIS under the allocation 2014-1523 made by GENCI.

The IPEV-CALVA, INSU-LEFE-CLAPA and OSUG GLACIOCLIM-CENACLAM projects are acknowledged for their support.

Edited by: S. Preunkert

\section{References}

Andreas, E. L., Claffey, K. J., and Makshtas, A. P.: Low-level atmospheric jets and inversions over the western Weddell sea, Bound.Lay. Meteorol., 97, 459-486, 2000.

Banta, R. M., Pichugina, Y. L., and Newsom, R. K.: Relationship between low-level jet properties and turbulence kinetic energy in the nocturnal stable boundary layer, J. Atmos. Sci., 60, 25492555, 2003.

Barral, H., Vignon, E., Genthon, C., Bazile, E., Traullé, O., Gallée, H., Brun, C., Couvreux, F., and Le Moigne, P.: Summer diurnal cycle at Dome $\mathrm{C}$ on the Antarctic plateau, in: Proceeding of the AMS 21st Symposium on Boundary Layers and Turbulence, 9-13 June 2014, Leeds, UK, poster session 1, paper 14, 2014.

Bintanja, R.: Snowdrift suspension and atmospheric turbulence. Part I: Theoretical background and model description, Bound.Lay. Meteorol., 95, 343-368, 2000.

Blackadar, A. K.: Boundary layer wind maxima and their significance for the growth of nocturnal inversions, B. Am. Meteorol. Soc., 38, 283-290, 1957.

Cuxart, J., Holtslag, A. A. M., Beare, R. J., Bazile, E., Beljaars, A., Cheng, A., Conangla, L., Ek, M., Freedman, F., Hamdi, R., Kerstein, A., Kitagawa, H., Lenderink, G., Lewellen, D., Mailhot, J., Mauritsen, T., Perov, V., Schayes, G., Steeneveld, G.-J., Svensson, G., Taylor, P., Weng, W., Wunsch, S., and Xu, K.M.: Single-Column Model Intercomparison for a Stably Stratified Atmospheric Boundary Layer, Bound.-Lay. Meteorol., 118, 273-303, 2006.
Cuxart, J. and Jimenez, M. A.: Mixing processes in a nocturnal lowlevel jet: an LES study, J. Atmos. Sci., 64, 1666-1679, 2007.

Davies, P. A.: Development and mechanisms of the nocturnal jet, Meteorol. Appl., 7, 239-246, 2000.

Duynkerke, P. G. and Driedonks, A. G. M.: A model for the turbulent structure of the stratocumulus-topped atmospheric boundary layer, J. Atmos. Sci., 44, 43-64, 1987.

Gallee, H.: Simulation of the mesocyclonic activity in the Ross Sea, Antarctica, Mon. Weather Rev., 123, 2051-2069, 1995.

Gallée, H. and Schayes, G.: Development of a three-dimensional meso-gamma primitive equations model, katabatic winds simulation in the area of Terra Nova Bay, Antarctica, Mon. Weather Rev., 122, 671-685, 1994.

Gallée, H., Preunkert, S., Argentini, S., Frey, M. M., Genthon, C., Jourdain, B., Pietroni, I., Casasanta, G., Barral, H., Vignon, E., Amory, C., and Legrand, M.: Characterization of the boundary layer at Dome C (East Antarctica) during the OPALE summer campaign, Atmos. Chem. Phys., 15, 62256236, doi:10.5194/acp-15-6225-2015, 2015

Genthon, C., Town, M. S., Six, D., Favier, V., Argentini, S., and Pellegrini, A.: Meteorological atmospheric boundary layer measurements and ECMWF analyses during summer at Dome C, Antarctica, J. Geophys. Res.-Atmos., 115, D05104, doi:10.1029/2009JD012741, 2010.

Genthon, C., Six, D., Gallée, H., Grigioni, P., and Pellegrini, A.: Two years of atmospheric boundary layer observations on a $45 \mathrm{~m}$ tower at Dome C on the Antarctic plateau, J. Geophys. Res.Atmos., 118, 3218-3232, doi:10.1002/jgrd.50128, 2013.

King, J. C., Argentini, S., and Anderson, P. S.: Contrasts between the summertime surface energy balance and boundary layer structure at Dome C and Halley stations, Antarctica, J. Geophys. Res.-Atmos., 111, D02105, doi:10.1029/2005JD006130, 2006.

Mahrt, L.: Momentum balance of gravity flows, J. Atmos. Sci., 39, 2701-2711, 1982.

Neff, W., Helmig, D., Grachev, A., and Davis, D.: A study of boundary layer behavior associated with high NO concentrations at the South Pole using a minisodar, tethered balloon, and sonic anemometer, Atmos. Environm., 42, 2762-2779, 2008.

Sukoriansky, S., Galperin, P., and Veniamin, P.: Application of a new spectral theory on stably stratified turbulence to the atmospheric boundary layer over sea ice, Bound.-Lay. Meteorol., 117, 231-257, 2005.

Van de Wiel, B. J. H., Moene, A. F., Steeneveld, G. J., Baas, P., Bosveld, F. C., and Holtslag, A. A. M.: A Conceptual View on Inertial Oscillations and Nocturnal Low-Level Jets, J. Atmos. Sci., 67, 2679-2689, doi:10.1175/2010JAS3289.1, 2010. 